\title{
Preprint: Data on Peer Reviewed Papers about Recreational Disturbance of Coastal Avifauna
}

\author{
Greg D. Simpson 1,2,t,* - https://orcid.org/0000-0003-4926-5491 \\ Sumudu Marasinghe $3,+$ - https://orcid.org/0000-0002-4604-4573 \\ David Newsome 2,4 - http://orcid.org/0000-0003-1482-6703 \\ Priyan Perera ${ }^{3}$ - https://orcid.org/0000-0002-9452-4790 \\ 1 Harry Butler Institute, Centre for Sustainable Aquatic Ecosystems, Murdoch University, South Street, \\ Perth, 6150, WA, Australia \\ 2 Sukau Ecotourism Research Center (SERC), BEST Society, Lot 1, Pusat Perindustrian, Kolombong Jaya, \\ Jalan Kolombong, 88450 Kota Kinabalu, Sabah, Malaysia. \\ 3 Department of Forestry and Environmental Sciences, University of Sri Jayewardenepura, Gangodawila, \\ Nugegoda 10250, Sri Lanka \\ 4 College of Science. Health, Engineering and Education, Environmental and Conservation Sciences, \\ Murdoch University, South Street, Perth, 6150, 6150, WA, Australia \\ + Co-First Authors \\ * Correspondence: G.Simson@Murdoch.edu.au
}

\begin{abstract}
This data descriptor summarizes the process applied to identify, screen, select and gather data from the content of 142 peer-reviewed papers/sources that report on the sources and impacts of recreational disturbance on coastal avifauna. While populations of resident and migratory coastal avifauna are under threat and diminishing rapidly across the planet, and particularly in association with Asian flyways, many governments are leveraging booming global demand for coastal recreation and tourism in order to deliver economic development to regional communities. The summary data shared via this data description was extracted from papers collected in a systematic literature review that was designed to explore the global literature on the recreational disturbance of coastal avifauna in order to elucidate the state of the global knowledge regarding this issue and to identify management strategies that could be applied at tropical Asian destinations to minimize the impacts of recreational disturbance and thus enhance the ecological sustainability of coastal recreation and tourism across the region. The data shared via the Excel worksheet associated with this data descriptor was extracted from peer-reviewed articles published in English between 1 January 2000 and the 31 December 2018 with the full text of the article available online. These articles were found by searching several online indexing several databases including Scopus, Web of Science, ProQuest and Google Scholar.
\end{abstract}

Dataset: The dataset is published a supplement to this Data Descriptor.

Dataset License: CC-BY

Keywords: beaches; coastal avifauna; ecotourism; migratory birds; recreation ecology; recreational disturbance; shorebirds; tourism development; wetlands 


\section{Summary}

Against a backdrop of a world-wide decline in the abundance of coastal avifauna, especially amongst populations of migratory species, many governments are leveraging booming global demand for coastal recreation and tourism to deliver economic development communities living in coastal areas [1-7]. The provision of infrastructure and increased human use of coastal areas arising from the development of recreation and tourism can significantly degrade the quality of highly diverse and fragile ecosystems of coastal areas [8-10]. Those coastal ecosystems, especially shorelines and wetlands, are significant habitats for avifauna, providing stop-over sites for migratory bird species and are essential for shorebird breeding, roosting and foraging [11, 12].

In addition to the impacts of habitat loss, coastal avifauna are disturbed by the plethora of recreational activities that humans are enjoying in coastal environs, forcing birds to leave the area temporarily or permanently depending on the severity of the disturbance $[8,13]$. Ecological disturbance is defined as the disruption of the normal activity or physiology of an animal in response to stimuli $[14,15]$. Cayford [16] defined recreational disturbance of avifauna to be any relatively discrete event that disrupts ecosystems, communities or populations, where disruption refers to a change in behaviour, physiology, abundance or survival of individuals or groups of birds. Many authors have reported that recreational disturbance is a major threat to coastal avifauna [e.g. 17-20].

Publication of this dataset has the potential to benefit others who are researching, planning, developing and managing coastal areas, especially in relation to the provision of recreational and tourism opportunities and the conservation and protection of coastal avifauna.

\section{Data Description}

The data were manually extracted from each of the 142 peer-reviewed papers included in the systematic review of Marasinghe et al. [8] and captured in Microsoft Excel that is shared as a worksheet in the supplementary materials associated with this data descriptor. The metadata for that worksheet are provided in Table 1.

The Abstract for each paper included in the systemic literature review was also captured and was used to inform the review article of Marasinghe et al. [8], but has been excluded from this data set for reasons of copyright.

\section{Methods}

Similar to the methods reported in the MDPI published reviews of Parker, Patroni, Walker and others [21-24] and the Data Descriptor of Simpson and others [25, 26], the data reported in this data descriptor was gathered as part of a systematic quantitative literature review that was based on the approach of Pickering and Byrne [27] and the Preferred Reporting Items for Systematic Reviews (PRISMA) guidelines [28].

The systematic quantitative literature review that we report in Marasinghe et al. [8] explored the following five research questions:

1. Where is the current research into the recreational disturbance of birds that use the coastal habitats being conducted?

2. What are the reported sources of recreational disturbance for birds using coastal habitats?

3. What are the reported impacts of recreational disturbance for birds using coastal habitats?

4. What management strategies are recommended to reduce the recreational disturbance of birds using coastal habitats?

5. What are the implications of this systematic quantitative literature review for the management of recreational disturbance of birds using coastal zones in Tropical Asia? 
Table 1. Metadata for dataset shared via the Excel worksheet as provided as supplementary material.

\begin{tabular}{|c|c|c|}
\hline Descriptors & Data Type & Description \\
\hline Paper ID & Numeric & $\begin{array}{l}\text { Assigned by researchers. } 1 \text { to } 142 \text { to provide a unique } \\
\text { identifier for each paper included in the review. }\end{array}$ \\
\hline Year & Numeric & Calendar year in which paper was published. \\
\hline Title & Text & Title of paper \\
\hline APA In-Text Citation & Text & APA formatted in-text reference for paper/source \\
\hline Journal/Source & Text & Name of journal that published paper \\
\hline Location & Text & Place where research was performed or 'Not Specified' \\
\hline Country & Text & $\begin{array}{l}\text { Country where research was performed or 'Global' for review } \\
\text { papers and other broad scale studies. }\end{array}$ \\
\hline Study Zone & Categorical & Aquatic, Terrestrial or Both \\
\hline $\begin{array}{l}\text { Mega-Region or } \\
\text { Continent }\end{array}$ & Text & Highest level of classification for location of study \\
\hline Ocean Zone & Text & Ocean(s) adjacent to site of study reported in article \\
\hline Koppen Climate Zone & Categorical & Classified according to Koppen Criteria \\
\hline Type of Research & Categorical & $\begin{array}{l}\text { Ecological, Human Dimensions, Review Article, Ecological \& } \\
\text { Human Dimensions. }\end{array}$ \\
\hline Research Method & Categorical & $\begin{array}{l}\text { Experimental, Observation, Traditioal Review, Both Ecological } \\
\text { \& Observational. }\end{array}$ \\
\hline Recreational Disturbance & Text & Short description of reported recreational disturbance(s) \\
\hline $\begin{array}{l}\text { Category of Recreational } \\
\text { Disturbance }\end{array}$ & Text & $\begin{array}{l}\text { A higher level classification of sources of recreational } \\
\text { disturbance recorded in preceding column of worksheet. }\end{array}$ \\
\hline Affected Behavior & Text & Short description of impacted or observed change in behavior. \\
\hline Type of Impact & Binary & Negative or Positive \\
\hline Primary Impact & Text & $\begin{array}{l}\text { Short summary of direct impacts on coastal avifauna exposed } \\
\text { to recreational disturbance. }\end{array}$ \\
\hline Secondary Impact & Text & $\begin{array}{l}\text { Short summary of indirect impacts on coastal avifauna as } \\
\text { individuals or populations exposed to recreational } \\
\text { disturbance. }\end{array}$ \\
\hline $\begin{array}{l}\text { Recommended } \\
\text { Management. Actions }\end{array}$ & Text & $\begin{array}{l}\text { Management actions/strategies recommended in paper to } \\
\text { reduce the impact(s) of recreational disturbance on coastal } \\
\text { avifauna }\end{array}$ \\
\hline $\begin{array}{l}\text { Implications for } \\
\text { Tropical Asia }\end{array}$ & Text & $\begin{array}{l}\text { Learnings for the conservation and/or protection on the } \\
\text { tropical Asian region derived from the paper. }\end{array}$ \\
\hline
\end{tabular}

Academic publications were identified by manually searching the Google Scholar, ProQuest, Scopus, and Web of Science indexing databases using the combination of search terns shown in Table 2. The other parameters initially specified to identify the papers that would be manually screened for inclusion in the systemic review were that publications should be peer-reviewed material published in the period from 1 January 2000 to 31 December 2018 with the full text available online. The PRISMA flow diagram for the systematic review reported in Marasinghe et al. [8] is shown in Figure 1.

Table 2. Search terms used to identify papers included in the literature review. Potential papers were filtered using the primary AND secondary search term in the preliminary search.

\begin{tabular}{cc}
\hline Primary Search Terms & Secondary Search Terms \\
\hline "coastal avifauna" & "impact of ecotourism" \\
"coastal birds" & "nature-based tourism" \\
"shore birds" & "recreational disturbance" \\
shorebirds & "behavioral responses" \\
waders & \\
\hline
\end{tabular}



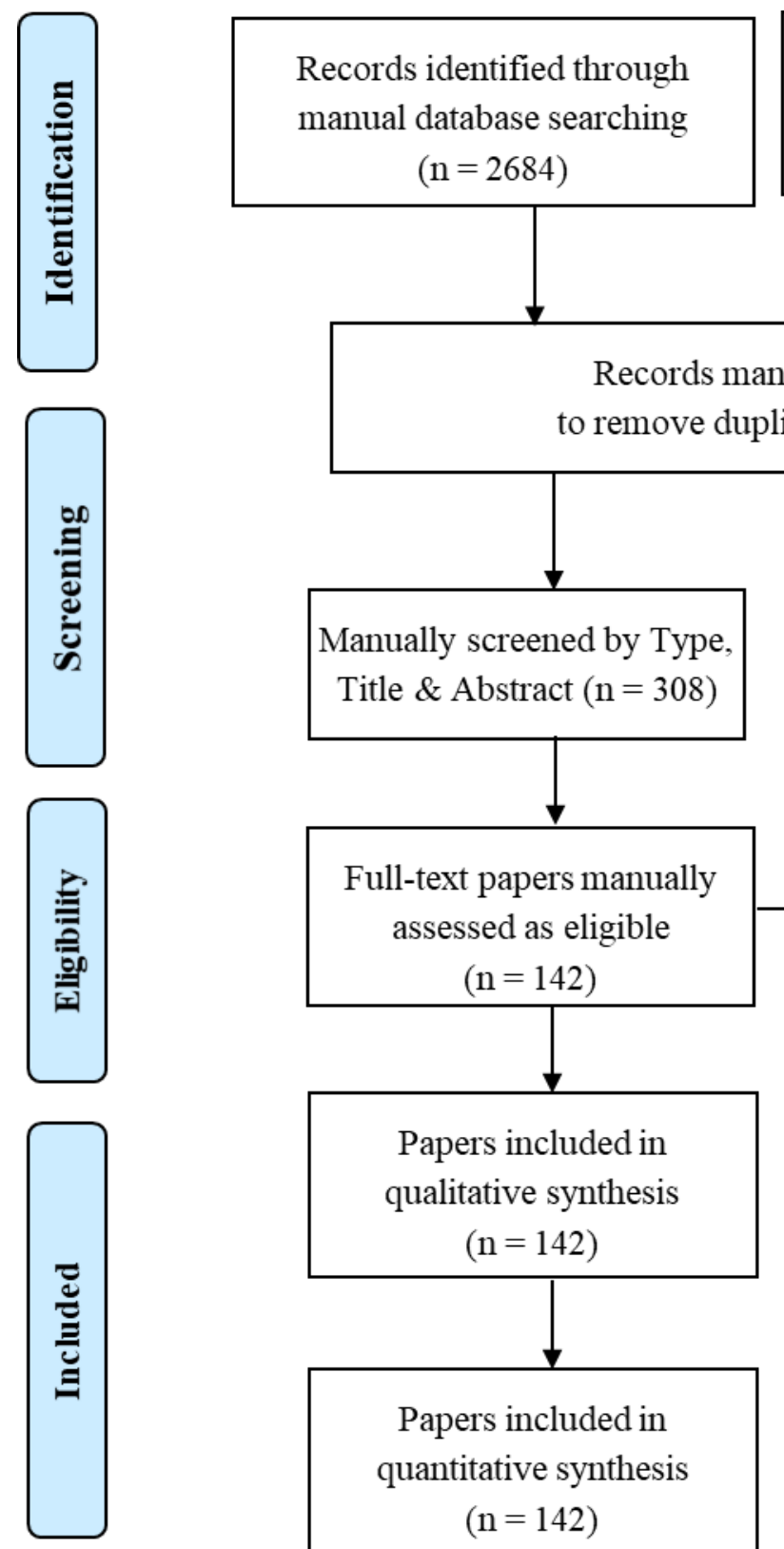

Additional records manually identified through other sources
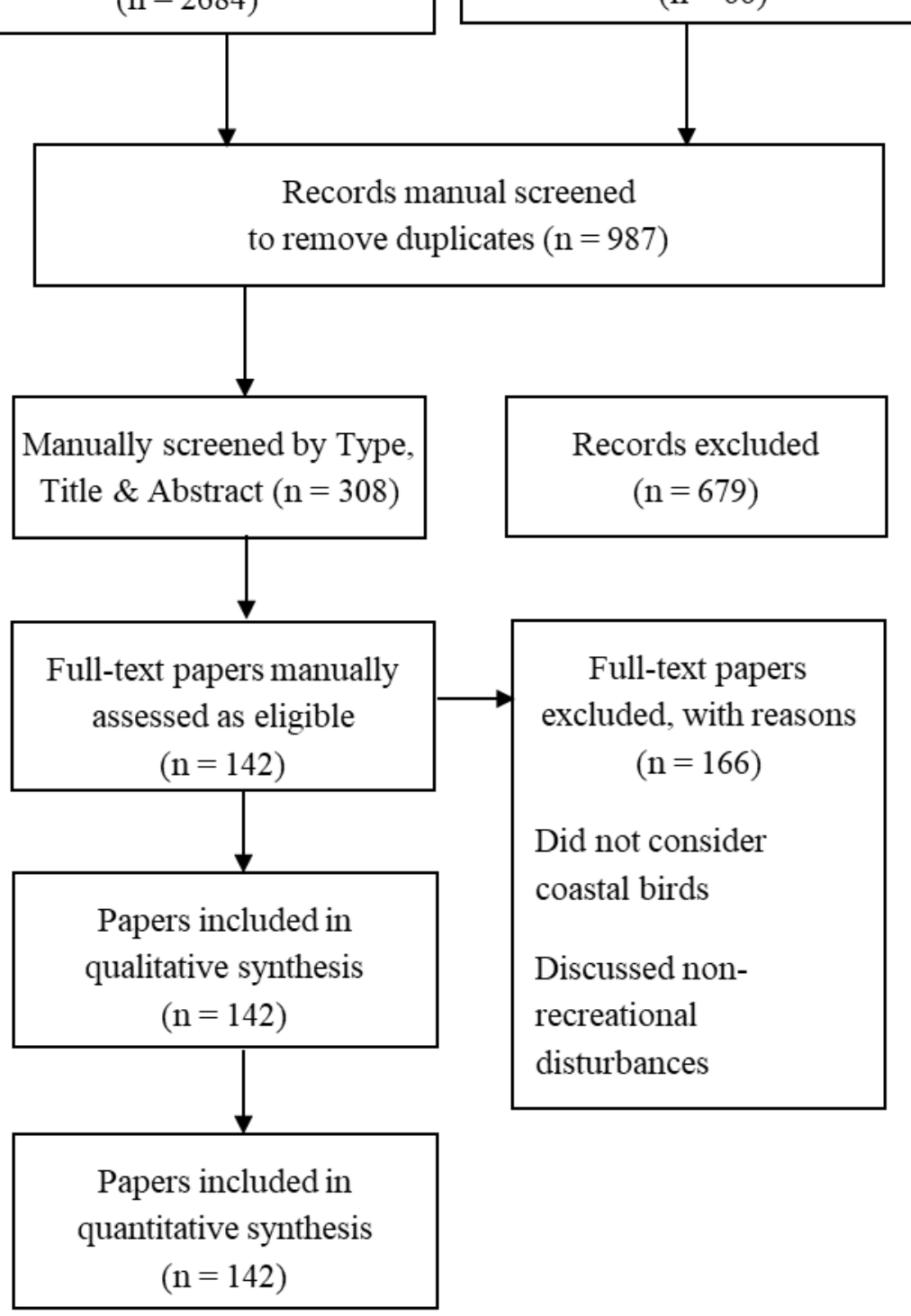

Figure 1: PRISMA flow diagram of the systemic process for paper identification and selection for inclusion in quantitative literature review article.

Supplementary Materials: Dataset shared as Preprint Dataset for Coastal Avifauna Systematic Review.xls

Author Contributions: S.M. completed the manual searches and initial data extraction for the systemic review. G.D.S and S.M. contributed equally to completing the systematic review, structuring of the dataset and writing of this data descriptor and as such are co-first authors. D.N. and P.P provided supervision for the project informed by the systemic review and contributed to the final review and editing of this data descriptor. P.P acquired the funding for the research informed by this systemic literature review.

Funding: The research informed by the systemic literature that produced the dataset shared via this data descriptor was funded by the National Research Council, Sri Lanka, grant number NRC 16-128. Assistance was provided by Center for Sustainability of the Department of Forestry and Environmental Science, University of Sri Jayewardenepura, Sri Lanka and Environmental and Murdoch University Conservation Sciences, College of Science, Health, Engineering, and Education. 
Acknowledgments: We wish to thank the Editors and Reviewers whose insightful comments enhanced the quality of our paper.

Conflicts of Interest: The authors declare no conflict of interest.

\section{References}

1. Hitchcock, M.; T King, V.; Parnwell, M. Heritage Tourism in Southeast Asia. Nias Press: Copenhagen, Denmark, 2010, pp. 320.

2. Holden, A. An Introduction to Tourism-Environment Relationships. In J Hill and T Gale (eds.). Ecotourism and Environmental Sustainability: Principal and Practice. Ashgate Publishing Limited: Cornwell, United Kingdom, 2016, pp. 17-30.

3. Larson, C. Hostile shores. Science 2015, 350(6257), 150-152. https://doi.org/10.1126/science.350.6257.150

4. Lilleyman. A.; Alley, A.; Jackson, D.; O'Brien, G.; Garnett S.T. Distribution and abundance of migratory shorebirds in Darwin Harbour, Northern Territory, Australia. Northern Territory Naturalist 2018, 28, 30-42.

5. Sachs J.D. From Millennium Development Goals to Sustainable Development Goals. The Lancet 2012, 379(9832), 2206-2211. https://doi.org/10.1016/S0140-6736(12)60685-0

6. United Nations World Tourism Organization. Tourism and the SDGs. http://www2.unwto.org/content/tourism-and-sdgs (accessed on 31 March 2019).

7. Ziegler, J.A.; Silberg, J.N.; Araujo, G.; Labaja, J. Ponzo ,A.; Rollin, R.; Dearden, P. A guilty pleasure: Tourist perspectives on the ethics of feeding whale sharks in Oslob, Philippines. Tourism Management 2018, 68, 264274. https://doi.org/10.1016/j.tourman.2018.04.001

8. Marasinghe, S.; Simpson, G.D.; Newsome, D.; Perera, P. Exploring the Current State of Knowledge Regarding the Recreational Disturbance of Coastal Avifauna with Insights for Tropical Asia. Sustainability, In Review.

9. Phillips, N.; Newsome, D. Understanding the impacts of recreation in Australian protected areas: Quantifying damage caused by horse riding in D'Entrecasteaux National Park, Western Australia. Pacific Conservation Biology 2001, 7(4), 256-273. https://doi.org/10.1071/PC020256

10. Simpson G.D.; Newsome D. Environmental history of an urban wetland: from degraded colonial resource to nature conservation area. Geo: Geography and Environment, 2017 4(1): e00030. https://doi.org/10.1002/geo2.30

11. Dowling, B.; Weston, M.A. Managing a breeding population of the Hooded Plover Thinornis rubricollis in a high-use recreational environment. Bird Conserv. Int. 1999, 9(4), 255-270.: https://doi.org/10.1017/s0959270900003440

12. Maslo, B.; Handel, S.N.; Pover, T. Restoring beaches for Atlantic coast piping plovers (Charadrius melodus): a classification and regression tree analysis of nest-site selection. Restor. Ecol. 2011, 19, 194-203. https://doi.org/10.1111/j.1526-100x.2010.00709.x

13. Geering, A.; Agnew, L.; Harding, S. Shorebirds in Australia, CSIRO Publishing: Melbourne, Australia, 2007, pp. 1998-1999.

14. McLeod, E.M.; Guay, P.J.; Taysom, A.J.; Robinson, R.W.; Weston, M.A. Buses, Cars, Bicycles and Walkers: The Influence of the Type of Human Transport on the Flight Responses of Waterbirds. PLoS One 2013, 8(12), e82008. https://doi.org/10.1371/journal.pone.0082008

15. Weston, M.A.; Antos, M.J.; Glover, K. Birds, Buffers and Bicycles: A Review and Case Study of Wetland Buffers. The Victorian Naturalist 2009, 126(3): 79-86.

16. Cayford, J. Wader disturbance: a theoretical overview. Wader Study Group Bulletin 1993, 68, 3-5

17. Drewitt, A.L. Birds and Recreational Disturbance. Ibis 2007, 149(1), 1-2. https://doi.org/10.1111/j.1474919x.2007.00663.x

18. Oldland, J.; Rogers, D.; Clemens, R.; Berry, L.; Maguire, G.; Gosbell, K. Shorebird Conservation in Australia: Birds Australia Conservation Statement, no. 14. Birds Australia. 2009, https://www.birdlife.org.au/documents/OTHPUB-shorebirds09.pdf (accessed on 8 June 2019)

19. Stillman, R.A.; West, A.D.; Caldow, R.W.; Durell, S.E.L.V.D. Predicting the effect of disturbance on coastal birds. Ibis 2007, 149(1), 73-81. https://doi.org/10.1111/j.1474-919X.2007.00649.x

20. Trulio, L.A.; White, H.R. Wintering Waterfowl Avoidance and Tolerance of Recreational Trail Use. Waterbirds 2017, 40(3), 252-262. https://doi.org/10.1675/063.040.0306

21. Parker, J.; Simpson, G. Public Green Infrastructure Contributes to City Liveability: A Systematic Quantitative Review. Land 2018, 7(4), 161. https://doi.org/10.3390/land7040161. 
22. Parker, J.; Zingoni de Baro, M.E. Green Infrastructure in the Urban Environment: A Systematic Quantitative Review. Sustainability 2019, 11(11), 3182. https://doi.org/10.3390/su11113182

23. Patroni, J.; Simpson, G.; Newsome, D. Feeding wild fish for tourism - A systematic quantitative literature review of impacts and management. International Journal of Tourism Research 2018, 20(3), 286-298. https://doi.org/10.1002/jtr.2180

24. Walker, O., Simpson, G.D., Teo, A.C.K. and Newsome, D. Preprint: Crowdsourcing and Analysing Wildlife Tourism Data from Photographs Shared on Social Media. Preprints 2019, 201908022. https://doi.org/10.20944/preprints201908.0226.v1

25. Simpson, G.D.; Parker, J. Data on Peer-Reviewed papers about green infrastructure, urban nature, and city liveability. Data 2018, 3(4), 51. https://doi.org/10.3390/data3040051

26. Simpson, G.D.; Walker, O. Preprint: Data from a Systematic Review of Crowdsourcing of Research Data from Wildlife Tourism Photographs and Comments Shared on Social Networking Sites. Preprints 2019, 2019080232. https://doi.org/10.20944/preprints201908.0232.v1

27. Pickering, C.M.; Byrne, J. The benefits of publishing systematic quantitative literature reviews for PhD candidates and other early career researchers. Higher Educ. Res. Dev. 2013, 33, 534-548. https://doi.org/10.1080/07294360.2013.841651

28. Moher, D.; Liberati, A.; Tetzlaff, J.; Altman, D.G. Preferred reporting items for systematic reviews and metaanalyses: The PRISMA statement. PLoS Med. 2009, 6, 1-6. 